\title{
Coaxial telescopic catheters systems in percutaneous diagnostic and therapeutic procedures
}

\author{
Grzegorz Smolka', Przemysław Żurek², Ewa Peszek-Przybyła ${ }^{1}$, Romuald Twardowski², Andrzej Ochała ${ }^{1}$ \\ ${ }^{13^{\text {rd }}}$ Division of Cardiology, Medical University of Silesia, Katowice, Poland \\ $2^{2}{ }^{\text {nd }}$ Division of Cardiology, Medical University of Silesia, Katowice, Polandd
}

Postep Kard Inter 2012; 8, 4 (30): 315-319

DOI: $10.5114 /$ pwki.2012.31912

\begin{abstract}
There are descriptions of the use of so-called telescopic systems in the literature concerning technical aspects of percutaneous therapeutic interventions within the heart or peripheral vessels. Those systems have either been built ad hoc, out of available instruments, or created as combined systems designed for such applications, which opens an opportunity to perform that kind of intervention in complicated anatomic systems. In the present paper the authors present application of telescopic systems in several areas of percutaneous interventions. The first includes coronary vessels in cases of additional anatomic complications such as significant aortic dilatation or very tortuous form of abdominal and thoracic aorta. Another area of application of telescopic systems includes peripheral vessels. As an example the authors describe procephalic and subclavian artery procedures here. The third area of interventions described in this article, where telescopic systems are applied, includes cases of structural heart diseases. The authors describe here the use of double and triple telescopic systems during procedures in patients with paravalvular (paramitral and paraaortal) leaks, as well as application of the above mentioned technique for passing a post-infarct ventricular septum defect. The discussion contains a presentation of previous reports on application of telescopic systems in various clinical situations, as well as limitations related to this method.
\end{abstract}

Key words: telescopic technique, coronary angioplasty, structural interventions

\section{Introduction}

Sometimes percutaneous interventions require passing though structures where, from the technical perspective, access is extremely difficult and equipment designated for such procedures is usually nonexistent.

In the literature concerning technical issues related to percutaneous interventions within the heart and peripheral vessels, we can find some reports on opportunities associated with guiding telescoping catheter sets and application of long vessel sheaths.

Those reports confirm better support for coronary angioplasty systems [1], as well as better support in structural interventions [2].

We make an attempt to review different diagnostic and therapeutic applications of telescopic technique.

\section{Coronary arteries}

Selective angiography in patients with significant $(>6 \mathrm{~cm})$ ascending aorta dilatation with a single catheter is difficult or often even impossible. One of the available options in such a case is application of a telescopic catheter system. We describe a patient with profound ascending aorta dilatation, qualified for the Bentall procedure, in whom ascending aorta dimension in MDCT was $8 \mathrm{~cm}$. Precise localization and assessment of coronary arteries was problematic due to concomitant fast atrial fibrillation. Therefore standard coronary angiography was performed: using femoral access we inserted a long $(90 \mathrm{~cm}) 6 \mathrm{~F}$ sheath, then a telescopic system consisting of a $100 \mathrm{~cm}$ EBU $3.56 \mathrm{~F}$ guiding catheter and $125 \mathrm{~cm}$ JL4 5 F diagnostic catheter was placed within the vessel sheath, thus making a triple telescopic system consisting of the vessel sheath, guiding catheter and diagnostic catheter, which was applied for selective left coronary artery LCA opacification (Fig. 1 A). Then after replacing the catheters with an AR2 $6 \mathrm{~F}$ guiding catheter and $125 \mathrm{~cm}$ JR4 $5 \mathrm{~F}$ diagnostic catheter, right coronary artery (RCA) angiography was performed (Fig. 1 B).

Other situations where coronary artery access is difficult may be considered an indication to apply this tech-

\section{Corresponding author:}

Grzegorz Smolka, 3'd Division of Cardiology, Medical University of Silesia, 47 Ziołowa St, 40-635 Katowice, Poland, tel.: + 48322024025 , e-mail: grsm18@wp.pl

Praca wpłynęła: 11.09.2012, przyjęta do druku: 13.09.2012. 
A
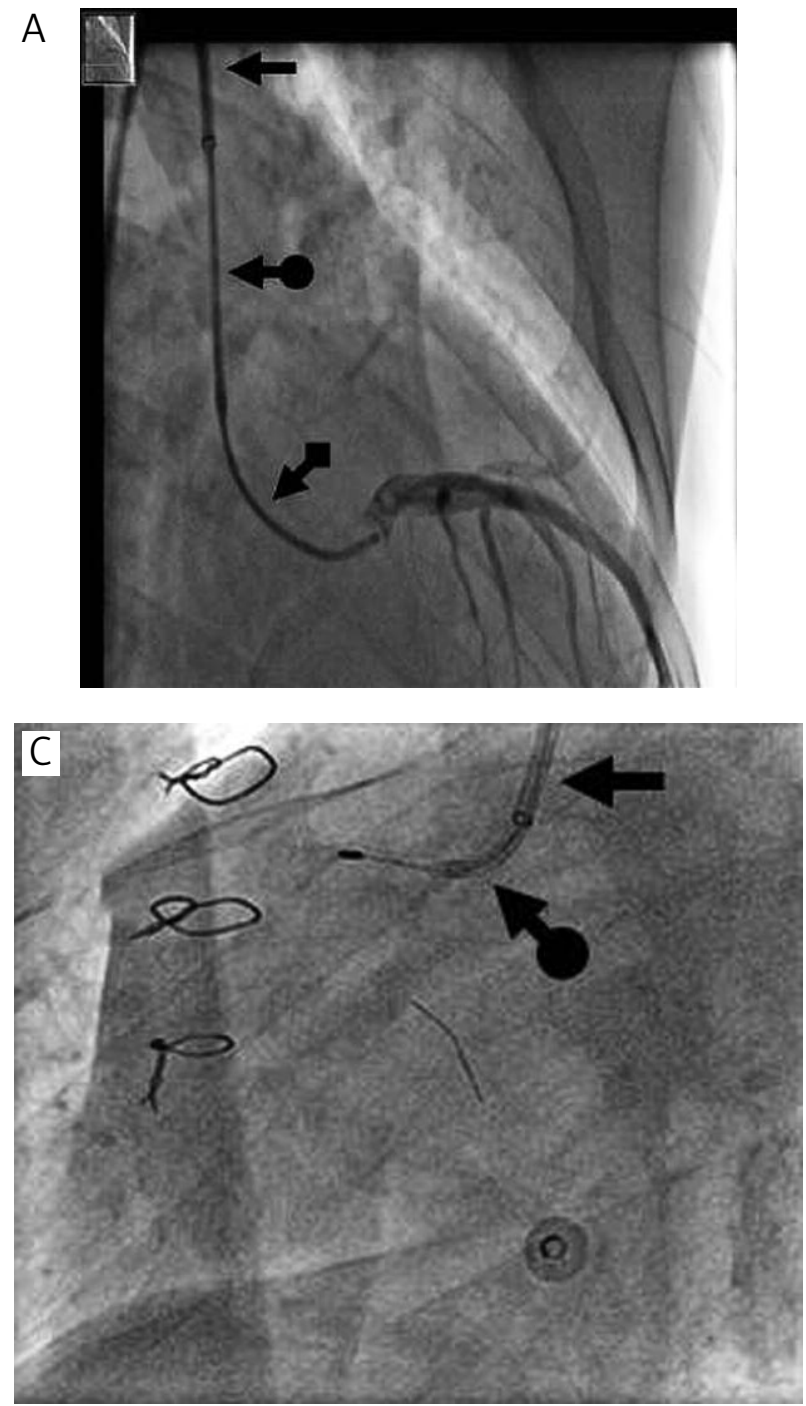

$\mathrm{B}$

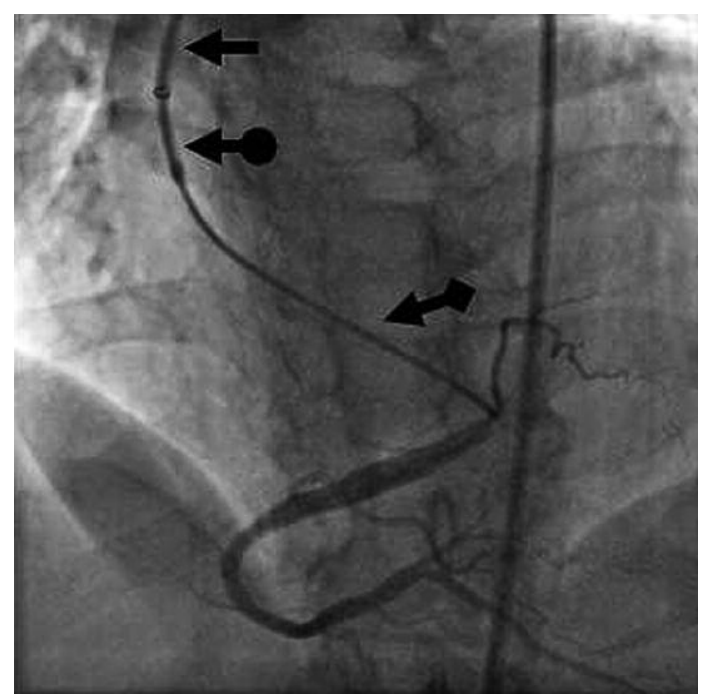

D

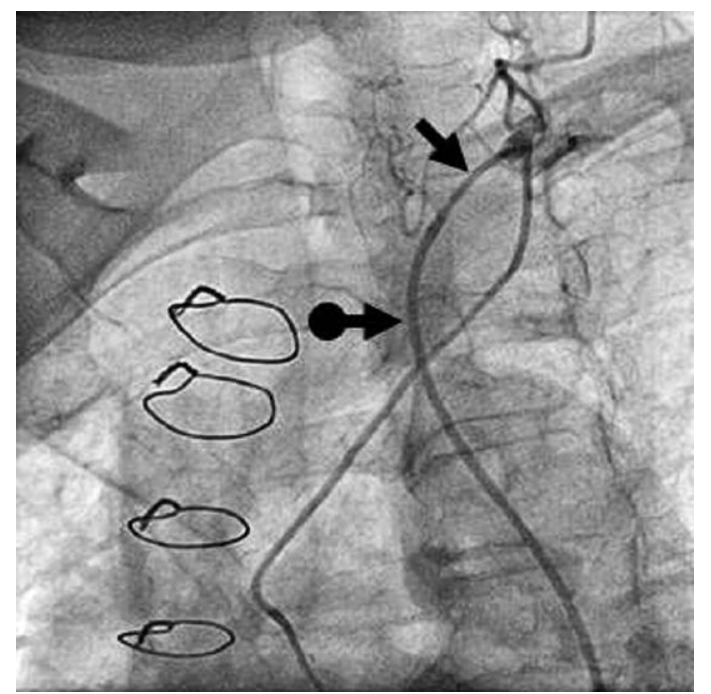

Fig. 1. A - LCA selective angiography; arrow - long $(90 \mathrm{~cm}) 6 \mathrm{~F}$ sheath; arrow with dot - EBU $3.56 \mathrm{~F}$ guiding catheter; arrow with square - JL $45 \mathrm{~F}$ diagnostic catheter. B - RCA selective angiography; arrow - long $(90 \mathrm{~cm})$ $6 \mathrm{~F}$ sheath; arrow with dot - AR2 $6 \mathrm{~F}$ guiding catheter; arrow with square - JR4 $5 \mathrm{~F}$ diagnostic catheter. C - RCA rotablation via femoral access; arrow - long $(90 \mathrm{~cm}) 6 \mathrm{~F}$ sheath; arrow with dot - JR4 $6 \mathrm{~F}$ guiding catheter. D - LIMA selective angiography; arrow - JR4 $5 \mathrm{~F}$ diagnostic catheter; arrow with dot - JR4 6 F guiding catheter

nique. We present an example of RCA ostial rotablation shown in Fig. $1 \mathrm{C}$. In this case the only available access through the right femoral artery (patient on hemodialysis) had been exploited. Moreover, tortuosity of iliac arteries and aorta made selective right coronary artery catheterization substantially more difficult.

The system we used here consisted of a long $(90 \mathrm{~cm})$ $6 \mathrm{~F}$ vessel sheath and JR4 $6 \mathrm{~F}$ guiding catheter, which allowed for very good catheter maneuvering, as well as for proper support for the rotablation system.

\section{Peripheral vessels}

Telescopic technique should be considered the classic one during procedures performed on peripheral vessels. A typical example is an internal carotid artery angioplas- ty where some aortic arch anatomical variations (arch type II or especially III), or situations where the only available access is through the brachial/radial arteries, make us use different telescopic systems. A good example is an angioplasty of the left internal carotid artery originating from the brachiocephalic artery (bovine arch) in a difficult type III aortic arch. A triple telescoping system consisting of a $6 \mathrm{~F}$ long vessel sheath, JR $6 \mathrm{~F}$ guiding catheter and JR $5 \mathrm{~F}$ diagnostic catheter was inserted through the right femoral artery (Fig. 2 A).

Another example of use of a telescopic system (JR4 $6 \mathrm{~F}$ guiding catheter $+125 \mathrm{~cm}$ JR4 $5 \mathrm{~F}$ diagnostic catheter) is in the case of a patient with a significantly deformed aortic arch and tortuous left subclavian artery (Fig. 1 D), where the aforesaid system was applied for selective angiography 
A

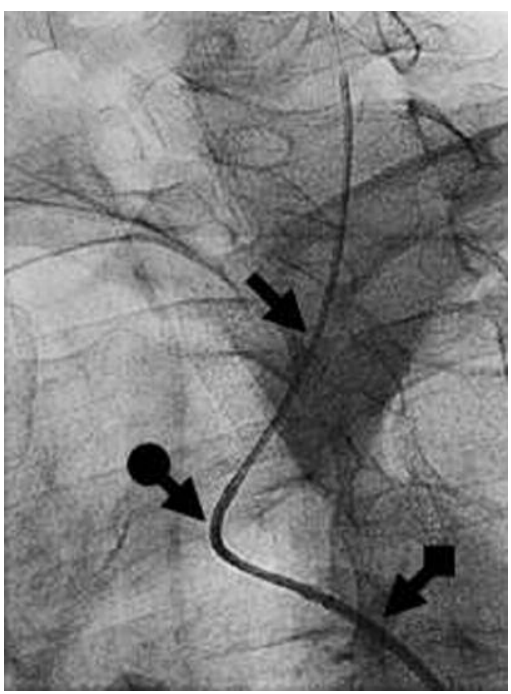

C

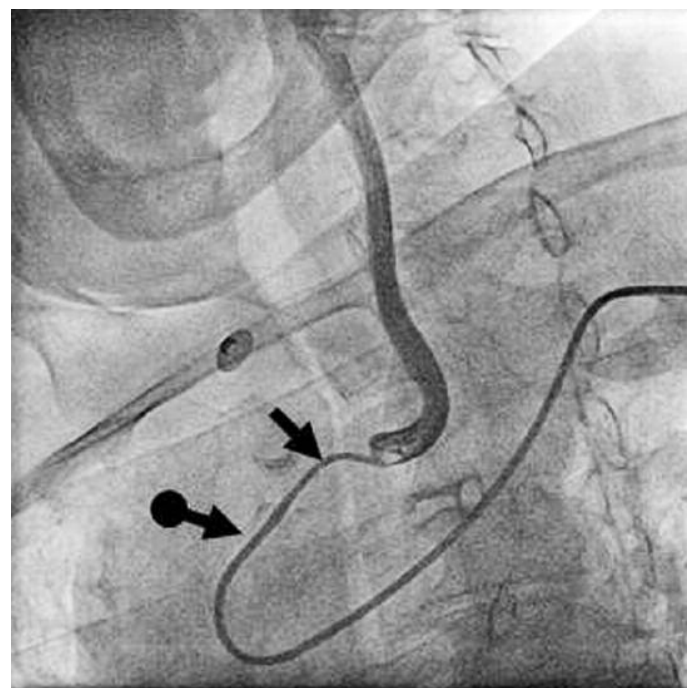

B

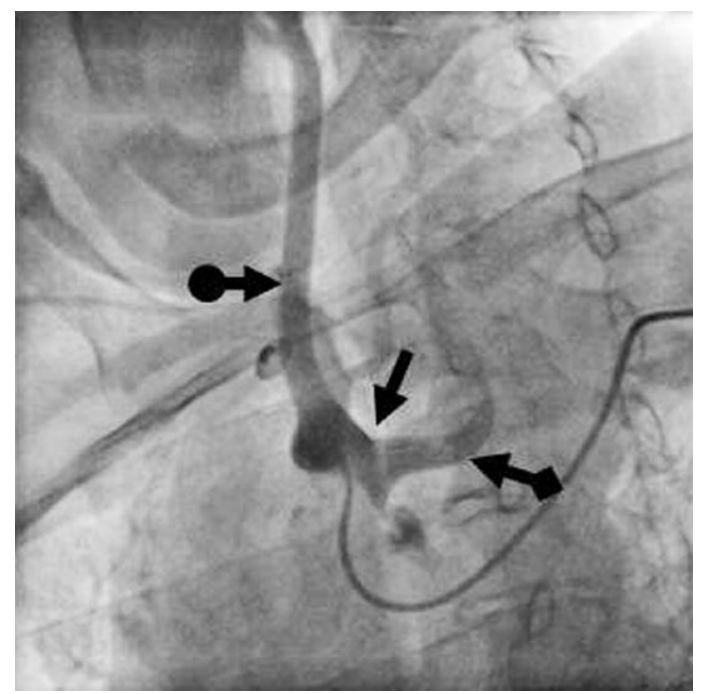

D

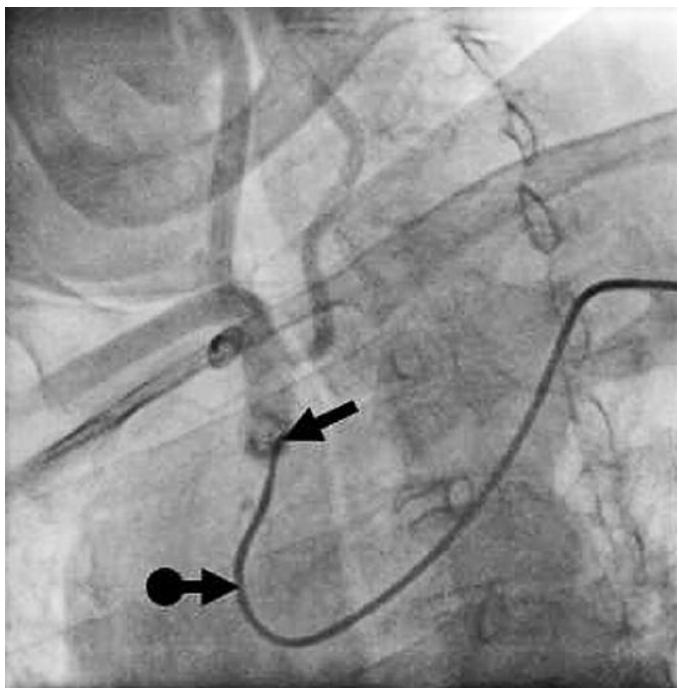

Fig. 2. A - LICA angioplasty via femoral access; arrow - JR4 $5 \mathrm{~F}$ diagnostic catheter; arrow with dot - JR4 6 F guiding catheter; arrow with square - long $(90 \mathrm{~cm}) 6 \mathrm{~F}$ sheath. B - Brachiocephalic artery angiography via left radial access; arrow - brachiocephalic artery; arrow with dot - right common carotid artery; arrow with square left common carotid artery. C - LCCA angiography via left radial access; arrow - JR4 $5 \mathrm{~F}$ diagnostic catheter; arrow with dot - AL1 $6 \mathrm{~F}$ guiding catheter. D - RCCA angiography via left radial access; arrow - JR4 $5 \mathrm{~F}$ diagnostic catheter; arrow with square - AL1 6 F guiding catheter

of the left internal mammal artery (LIMA). In another case selective angiography of the brachiocephalic artery (Fig. 2 B) and the left common carotid artery (LCCA) was performed via the left radial access with a telescopic system consisting of an AL1 6 F guiding catheter and JR 5 F diagnostic catheter (Fig. 2 C). The same set was also used for right common carotid artery (RCCA) angiography (Fig. 2 D).

\section{Structural heart diseases}

Application of telescopic systems is not restricted to coronary or peripheral vessel interventions only, but should be considered as one of the basic techniques applied in structural heart disease therapy as well. Several different, rotating, independently controlled bends combined in one system allows for reaching most of the intervention target areas. It is also helpful in atraumatic passing through of heart structures such as the ventricular septum injured by acute ischemia in a patient with post-infarct VSD (Figs. $3 \mathrm{C}$ and $3 \mathrm{D}$ ). In this case an AL2 6 F guiding catheter and longer $125 \mathrm{~cm}$ JR4 $5 \mathrm{~F}$ diagnostic catheter were used to localize and cross the septum defect.

In most cases of paravalvular leaks (PVL), localization and passing through the leak also requires application of complex telescopic technique.

In case of para-aortic leak localized in the left coronary sinus area (Fig. 3 A), a commonly used solution is to apply a combination of the outer AL type guiding catheter and smaller JR type diagnostic catheter as the inner catheter. 
A

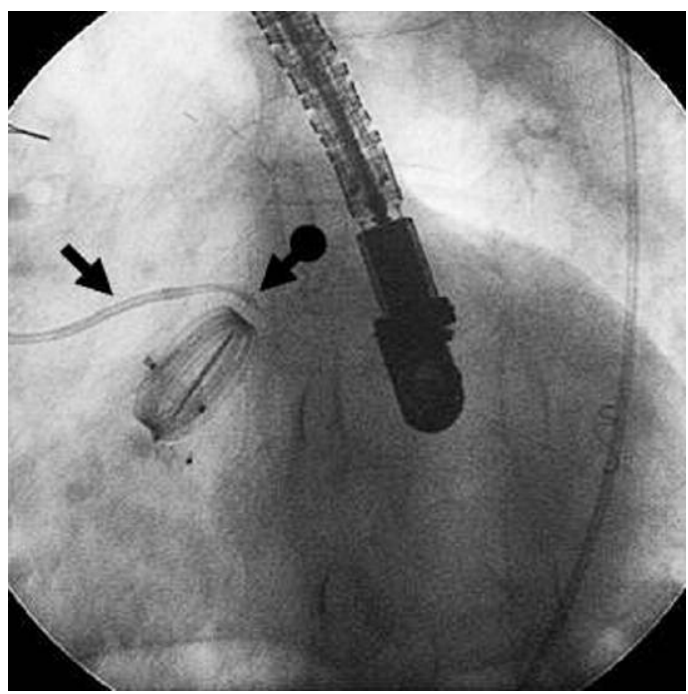

C

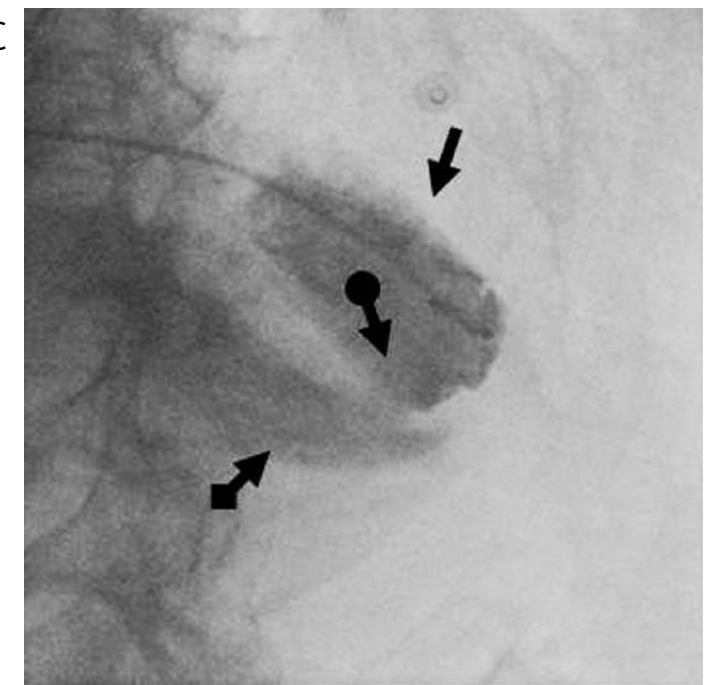

B

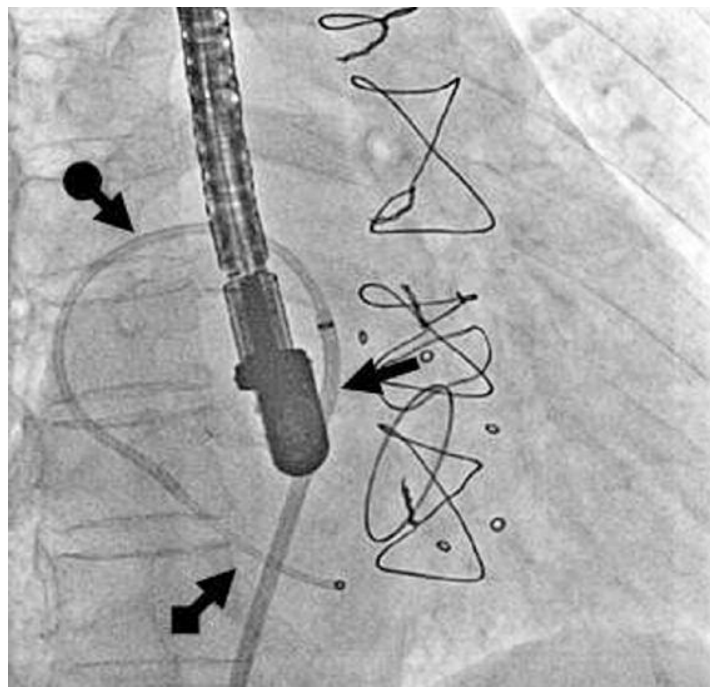

D

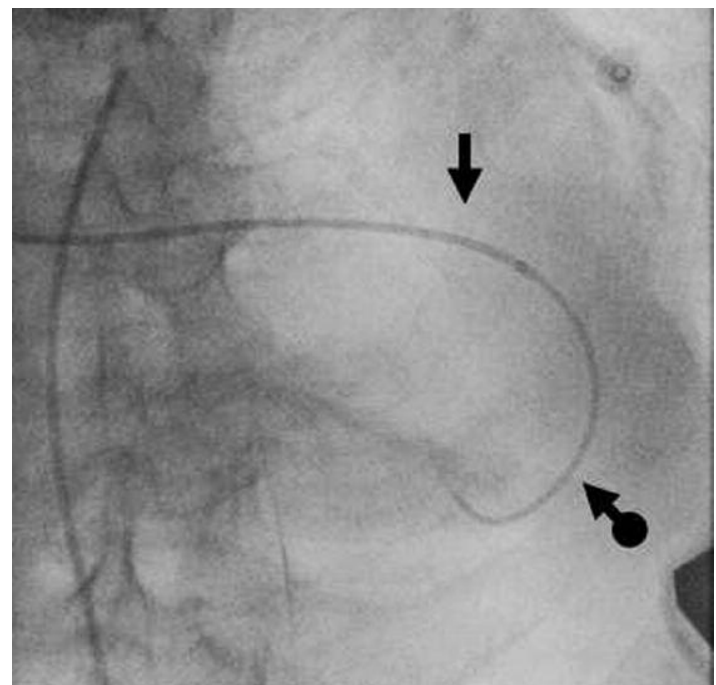

Fig. 3. A - Closure of para-aortic leak; arrow - AL1 6 F guiding catheter; arrow with dot - JR4 $5 \mathrm{~F}$ diagnostic catheter. B - Paramitral leak closure - loop created from 2 catheter system in the left atrium; arrow $-8 \mathrm{~F}$ transseptal sheath; arrow with dot - AL1 6 F guiding catheter; arrow with square - JR4 5 F diagnostic catheter. C - Left ventricular post-infarction septal defect; arrow - left ventricle; arrow with dot - post-infarct VSD; arrow with square - right ventricle. D - JR $5 \mathrm{~F}$ diagnostic catheter crossing IVS defect; arrow - JR4 6 F guiding catheter; arrow with dot - JR4 $5 \mathrm{~F}$ diagnostic catheter

In case of mitral paraprosthetic leaks, transseptal puncture with telescopic system application is frequently a must. In such cases (Fig. 3 B) a triple telescopic system is often applied (here $8 \mathrm{~F}$ transseptal sheath, AL1 $6 \mathrm{~F}$ guiding catheter and as inner catheter JR4 $5 \mathrm{~F}$ diagnostic catheter). The loop, created in the left atrium by the abovementioned system, facilitates obtaining an optimal alignment with the leak channel even if, as in our case, the leak is located in the paraseptal atrium area. In addition, gradually increasing system stiffness usually allows for crossing through the frequently quite tortuous leak canal.

\section{Discussion}

Application of telescopic systems often enables overcoming technical challenges related to difficult access to the intervention site, often available only through several multidimensional bends, as well as lack of proper support for devices inserted during the procedure. The first reports describe their extracardiac application in visceral, carotid and renal arteries [1-4]. Several papers have been published concerning technical difficulties related to selective artery catheterization in patients with a significantly dilated ascending aorta. The authors of those publications suggest application of AL3 $6 \mathrm{~F}+\mathrm{MP} 4 \mathrm{~F}$ [5], EBU4.5 $6 \mathrm{~F}+\mathrm{MPA} 1$ $4 \mathrm{~F} \mathrm{[6]}$ or Heartrail III $5 \mathrm{~F}$ type catheter placed inside the EBU4.0 $6 \mathrm{~F}$ guiding catheter [7].

An advantage of the triple system presented in our paper - long introducer, guiding catheter and diagnostic catheter - is that it allows for catheter position control even in a very dilated ascending aorta with no need to 
shore up the aortic wall, which significantly decreases the perforation risk. In addition, if a JL-shape guiding catheter is used, then its opening angle can be easily changed by moving the introducer forward and backward. On the other hand, the abovementioned rotablation where a telescopic system consisting of $6 \mathrm{~F}$ sheath and $6 \mathrm{~F}$ guiding catheter was used illustrates one of available possibilities of support for the applied devices. The aforesaid Heartrail type catheters used in the telescopic system are also applied for superselective coronary artery intubation, which increases the stability of the system. Moreover, coronary angioplasty, as well as stent implantation or aspiration thrombectomy, can be performed through the system lumen.

The Guideliner is the latest version of the superselective coronary catheter [11]. Internal diameter of this catheter is $0.056 "$, and contrary to the Heartrail type catheters, it does not require disconnection of the hemostatic valve from the guiding catheter. It is dedicated to superselective vessel catheterization and support for balloon catheters and stent delivery, but stuck rotablator drill removal with this catheter has also been described.

Another application field for telescopic systems is an intervention in patients with structural heart diseases such as paravalvular leaks and/or acquired defects of the left ventricular wall [14, 15].

This technique has some potential drawbacks such as a risk of introduction of air into the artery during internal system parts removal (Venturi effect). To avoid this effect, the use of hemostatic valves between all system elements is recommended (applicable only in the case of smaller catheter sizes). It is also crucial to remove an inner catheter(s) slowly, thus avoiding air being sucked into the system, as well as to monitor the blood backflow from a guiding catheter. In case of an intervention in a venous, low pressure part of the circulatory system, keeping an end of the telescoping system below the heart level is essential. Another major challenge associated with the telescopic system is a possibility of examined structures being damaged by an internal catheter's end due to interference with surrounding structures.

\section{References}

1. Okazaki M, Higashihara F, Koganemaru F. A coaxial catheter and steerable guidewire used to embolize branches of the splanchnic arteries. Am J Roentgenol 1990; 155: 405-406.

2. Kaminou T, Nakamura K, Matsuo R, et al. A triple coaxial catheter system for subselective visceral artery catheterization and embolization: preliminary clinical experience. Cardiovasc Intervent Radiol 1998; 21: 255-257.

3. Voigt K, Djindjian R. Super-selective cerebral angiography. III. Diagnostic use and therapeutic possibilities of the telescopic catheterization technic in the circulation area of the external carotid artery in man. Rofo 1976; 125: 214-218.

4. Klow NE, Paulsen D, Vatne K, et al. Percutaneous transluminal renal artery angioplasty using the coaxial technique. Ten years of experience from 591 procedures in 419 patients. Acta Radiol 1998; 39: 594-603.

5. Geijer H, Kahari A. Coaxial technique for catheterization of the coronary arteries with a very dilated ascending aorta. Catheter Cardiovasc Interv 2004; 62: 32-34.

6. Rigatelli G, Giordan M, Mantovani R, et al. "Telescopic" technique for selective coronary angiography in severely dilated ascending aorta. Catheter Cardiovasc Interv 2007; 69: 1078-1079.

7. Anantharaman R, Obaid D, Chase A. Telescoping catheter technique for enlarged aortas. Catheter Cardiovasc Interv 2009; 74: 1126-1128.

8. Takahashi S, Saito S, Tanaka S, et al. New method to increase a backup support of a 6 French guiding coronary catheter. Catheter Cardiovasc Interv 2004; 63: 452-456.

9. Mamas MA, Fath-Ordoubadi F, Fraser D. Successful use of the Heartrail III catheter as a stent delivery catheter following failure of conventional techniques. Catheter Cardiovasc Interv 2008; 71: 358-363.

10. Hadi HM, Fraser DG, Mamas MA. Novel use of the Heartrail catheter as a thrombectomy device. J Invasive Cardiol 2011; 23: 35-40.

11. Stys AT, Lawson W, Brown D. Extreme coronary guide catheter support: report of two cases of a novel telescopic guide catheter system. Catheter Cardiovasc Interv 2006; 67: 908-911.

12. Cola C, Miranda F, Vaquerizo B, et al. The Guideliner catheter for stent delivery in difficult cases: tips and tricks. J Interv Cardiol 2011; 24: 450-461.

13. Cunnington M, Egred M. GuideLiner, a child-in-a-mother catheter for successful retrieval of an entrapped rotablator burr. Catheter Cardiovasc Interv 2012; 79: 271-273.

14. Rihal CS, Sorajja P, Booker JD, et al. Principles of percutaneous paravalvular leak closure. JACC Cardiovasc Interv 2012; 5: 121-130.

15. Yuksel UC, Tuzcu EM, Kapadia SR. Percutaneous closure of a postero-medial mitral paravalvular leak: the triple telescopic system. Catheter Cardiovasc Interv 2011; 77: 281-285. 